\title{
CARACTERIZAÇÃO GEOLÓGICA-GEOMORFOLÓGICA DA BACIA DO RIO JUARA (ESPÍRITO SANTO, SUDESTE DO BRASIL)
}

\author{
Luiza Leonardi Bricalli ${ }^{(a)}$, Breno Scardua de Souza ${ }^{(b)}$ \\ (a) Centro de Ciências Humanas e Naturais/Universidade Federal do Espírito Santo, luiza.bricalli@ufes.br \\ (b) Centro de Ciências Humanas e Naturais / Universidade Federal do Espírito Santo, brenoscardua @ hotmail.com
}

\section{EIXO: SISTEMAS GEOMORFOLÓGICOS: ESTRUTURA, DINÂMICA E PROCESSOS}

\begin{abstract}
Resumo
Esta pesquisa teve como objetivo principal caracterizar a geologia e geomorfologia da bacia do Juara (Espírito Santo, sudeste do Brasil). A base metodológica utilizada integrou a elaboração de mapeamentos, perfil geológico-geomorfológico e análises de campo. Os mapas foram elaborados a partir do Modelo Digital de Elevação (MDE) - TOPODATA e processados no software ArcGIS 10.1 $1^{\mathrm{TM}}$. Em campo, foram verificadas, analisadas e validadas variáveis de litologia, de estrutura geológica, de altimetria, de declividade de talude, de rugosidade do relevo, de feições morfotectônicas,de falhas neotectônicas e de morfologias, registrados com máquina fotográfica com resolução de 26 megapixels e GPS (Global Position System). Com base na análise do relevo, litologia e estrutura em gabinete e em campo, foi possível identificar que a bacia do rio Juara está controlada pela litoestrutura, litologia e reflete as tensões neotectônicas, atuando nas rochas do Embasamento Pré-Cambriano e nas rochas dos Depósitos Sedimentares.
\end{abstract}

Palavras chave: neotectônica, morfotectônica, litoestrutura

\section{Título da seção}

O estado do Espírito Santo situa-se na região Sudeste do Brasil e apresenta uma heterogeneidade geológica e geomorfológica que resulta em um mosaico de ambientes fisiográficos presentes em todo território brasileiro, dividido em 2 (dois) compartimentos contrastantes: i) embasamento pré-cambriano, a oeste do estado; e ii) depósitos sedimentares cenozoicos (Formação Barreiras e sedimentos quaternários), a leste (BRICALLI, 2011).Tais compartimentos apresentam um forte controle litoestrutural e neotectônico, com diferentes eventos tectônicos, documentados, especialmente, na drenagem e no relevo do estado (BRICALLI e MELLO, 2009; RIBEIRO, 2010; BRICALLI, 2011).

Grande parte das bacias hidrográficas desse estado, estão inseridas nesse contexto (BUSATO, 2014; BUSATO e BRICALLI, 2015; MARIN e BRICALLI, 2015; COSTA e BRICALLI, 2015) e estudos sobre compartimentação geomorfológica tem sido utilizados para identificar o controle da litologia, das estruturas e da tectônica na evolução da paisagem.

Estudos relacionados com a compartimentação geológica-geomorfológica tem sido realizados no mundo e, principalmente, no Brasil (GATTO et. al, 1983; MENKE et al.,2008; MELO, 2010; COSTA E FALCÃO, 2011; BRICALLI, 2011;TRENTIN et al., 2012; HASUI et al., 2012;SCHIRMER e 
ROBAINA, 2013; MARQUES et. al, 2015), objetivando delimitar áreas com características semelhantes geológicas e geomorfológicas semelhantes. Esses estudos envolvem, em alguns casos, a utilização de técnicas de geoprocessamento voltados para geomorfologia e geologia (BRICALLI, 2011; BRICALLI, et. al, 2014; SILVA, 2014; BUSATO, 2014; COSTA e BRICALLI, 2015), integrada a análises de campo (BRICALLI, 2011; XAVIER e NETTO, 2014; SALAMUNI et al., 2013), objetivando validação das características geológicas e geomorfológicas, além de tornar a pesquisa de natureza geológica e geomorfologia completa, uma vez que, seus aspectos são analisados exclusivamente com a observação direta em campo.

Dessa forma, a presente pesquisa tem como objetivo a caracterização geológica-geomorfológica da bacia do rio Juara, município de Serra, estado do Espírito Santo, região sudeste do Brasil.

\section{2. Área de estudo}

\subsection{Localização e acessos}

A área de estudo corresponde a uma bacia hidrográfica - Bacia do rio Juara, localizada na porção central do estado do Espírito Santo, município de Serra, estado do Espírito Santo, região sudeste do Brasil (Erro! Fonte de referência não encontrada.).

A principal via de acesso é a rodovia BR-101 - uma das rodovias mais acessadas do Estado do Espírito santo - que conecta o estado de norte a sul, ligando os estados da Bahia e do Rio de Janeiro. No município de Serra essa rodovia faz ligação com o município de Fundão a norte e a cidade de Vitória, a sul - assim como o restante do Espírito Santo. 

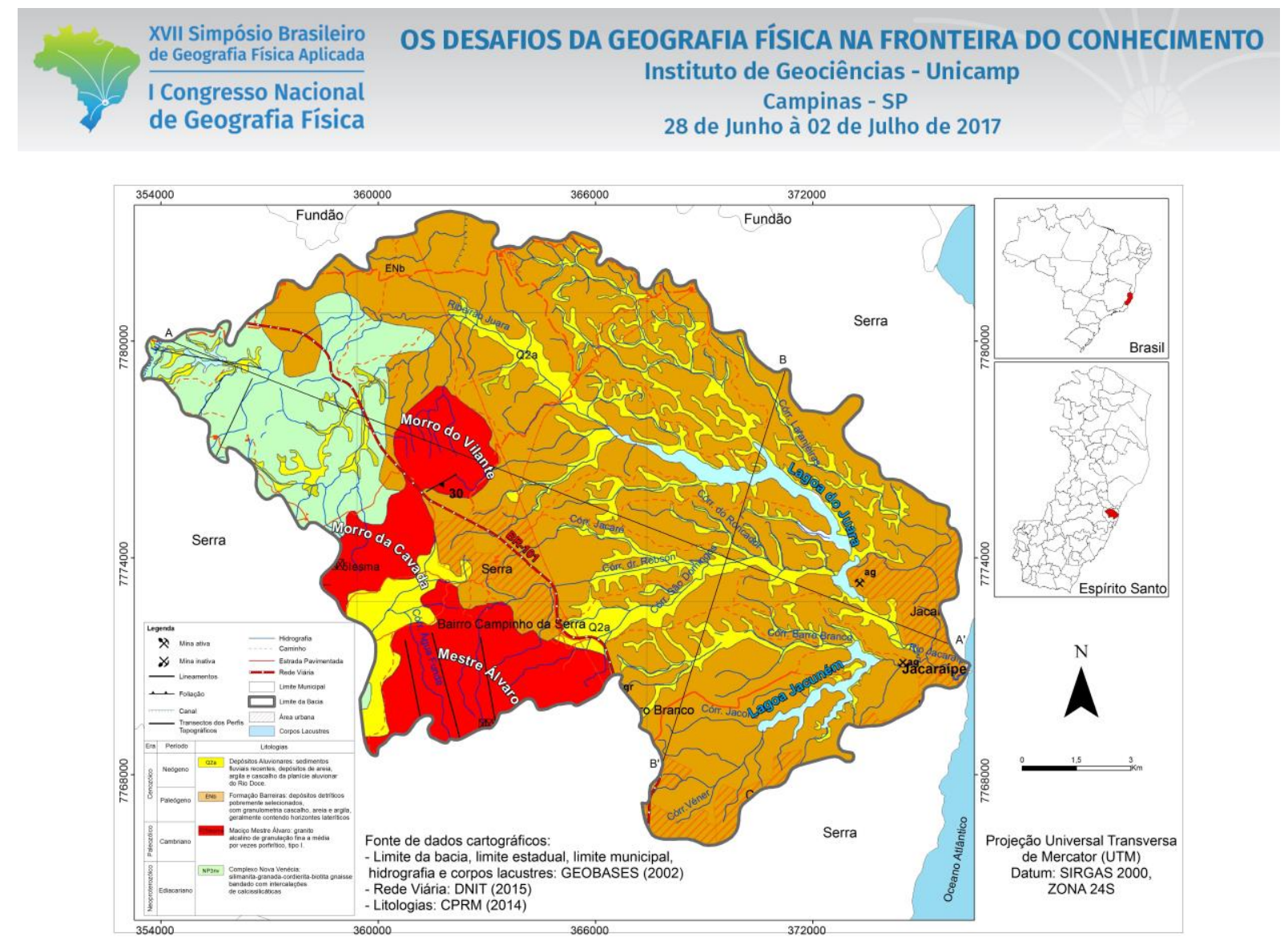

Figura 1 - Mapa geológico da bacia do rio Juara, mostrando os compartimentos geológicos "Depósitos Sedimentares", a leste e "Embasamento pré-cambriano, a oeste. Adptado de CPRM (2014).

\subsection{Geologia}

Geologicamente, o estado do Espírito Santo apresenta 2 (dois) compartimentos principais: i) Embasamento pré-cambriano, a oeste, constituído por rochas metamórficas e ígneas plutônicas proterozóicas e; ii) Depósitos sedimentares cenozoicos, a leste, representado pela Formação Barreiras e pelos depósitos quaternários, na porção emersa da bacia do Espírito Santo (BRICALLI, 2011).A bacia apresenta os dois compartimentos apresentados e estruturalmente encontra-se no Orógeno Araçuaí. Segundo Bricalli (2011), o orógeno corresponde a um cinturão móvel que se estende entre os paralelos $15^{\circ}$ e $21^{\circ} \mathrm{S}$, limitando-se a norte e a oeste pelo Cráton São Francisco e a leste pelas bacias do Espírito Santo e Mucuri. Divide-se em três compartimentos tectônicos: Domínio Externo, Domínio Interno e Inflexão Setentrional (HEILBRON et al., 2004).

No compartimento do embasamento pré-cambriano, a oeste da bacia, estão presentes as unidades Maciço Mestre Álvaro e Complexo Nova Venécia.

O Maciço Mestre Álvaro, presente na porção sul-sudoeste da área estudada (Figura 1 
Figura 1), apresenta composição de granito alcalino de granulação fina a média, por vezes porfirítico, tipo I da Era Paleozoica e do Período Cambriano (CPRM, 2014). Há presença de foliações e lineamentos bem marcados, estando os lineamentos situados no morro Mestre Álvaro, com orientação NNW-SSE e a foliação no Morro do Vilante, com caimento para sudeste.

O Complexo Nova Venécia se concentra, em sua totalidade, na porção extremo oeste da bacia, apresentando composição de silimanita-granada-cordierita-biotita gnaisse bandado com intercalações de calcissilicáticas, datados da Era Neoproterozóica e Período Ediacariano (CPRM, 2014) - figura 1

Figura 1. Apresenta lineamentos bem marcados, com orientação NNE-SSW (CPRM, 2014), na direção contrária dos lineamentos do morro Mestre Álvaro, descritos acima.

Segundo Bricalli (2011), estão presentes nas rochas do embasamento Pré-Cambriano uma quantidade expressiva de lineamentos, claramente associados a controles litoestruturais, nas orientações NE-SW, 


\section{OS DESAFIOS DA GEOGRAFIA FÍSICA NA FRONTEIRA DO CONHECIMENTO \\ Instituto de Geociências - Unicamp \\ Campinas - SP \\ 28 de Junho à 02 de Julho de 2017}

predominando na porção sul do estado, podendo ser explicado pela predominância de falhas, fraturas e foliações de direção NE-SW, relacionadas à estruturação da Faixa Ribeira, cortadas quase que perpendicularmente por estruturas de orientação NW-SE (MACHADO FILHO et al., 1983; PEDROSA SOARES e WIEDEMAN-LEONARDOS, 2000); orientações NNW-SSE, no domínio Faixa Colatina, na porção norte do estado, diretamente associado a esta feição estrutural no estado do Espírito Santo, mas, esses lineamentos também refletem as tensões neotectônicas na área.

No compartimento dos Depósitos Cenozoicos, a leste da bacia, estão presentes as unidades Formação Barreiras e Depósitos aluvionares.

A Formação Barreiras abrange a maior parte da bacia, presente na porção central, leste e norte (Figura 1). Apresenta em sua composição litológica depósitos detríticos pobremente selecionados, com granulometria cascalho, areia e argila - geralmente contendo horizontes lateríticos, datados do Mioceno (Neógeno) da Era Cenozóica (CPRM, 2014).

Segundo Bricalli (2011), existe uma quantidade significativa de lineamentos nos depósitos cenozoicos, especialmente na Formação Barreiras, com orientações E-W, NE-SW e NW-SE, que ocorrem de maneira expressiva e densidade significativa, podendo ser diretamente atribuídos aos padrões de fraturamento neotectônico na área.

Os Depósitos aluvionares estão presentes nos fundos de vales encaixados da Formação Barreiras, associados aos depósitos aluvionares quaternários, presentes na porção central (predominantemente) e nordeste da área (Figura 1

Figura 1). Encontram-se margeando o maciço granítico Mestre Álvaro, a sul da bacia e a oeste da área nos rios do Complexo Nova Venécia (Figura 1 
Figura 1). São compostos por sedimentos fluviais recentes, depósitos de areia, argila e cascalho da planície aluvionar do rio Doce, datados da época do Holoceno,do período Neógeno (CPRM, 2014).

\subsection{Geomorfologia}

O estado do Espírito Santo, região Sudeste do Brasil, segundo Ab' Saber (1998) insere-se no Compartimento Megageomorfológico Paleo-Abóboda do Escudo Brasileiro Transformada em Montanhas de Blocos Falhados, onde ocorrem os terrenos cristalinos de maior e mais persistente deformação em abóbada do Escudo Brasileiro. Trata-se de um mega domínio cristalino, de presença muito antiga, sujeito a diferentes fases de reativação, a par com complicações paleo-hidrográficas, devido às interferências da tectônica quebrável, a partir dos meados do Terciário. O mega domínio do Brasil de Sudeste teve continuada atuação, a diferentes níveis tectônicos, desde o Carbonífero superior até nossos dias (AB' SABER, 1998).

A bacia estudada apresenta 3 (três) unidades geomorfológica: i) Colinas e Maciços Costeiros; ii) Tabuleiros Costeiros e; iii) Planícies Costeiras (GATTO et al., 1983)Erro! Fonte de referência não encontrada..

A unidade Colinas e Maciços Costeiros é caracterizada por colinas côncavo-convexas e um conjunto morfológico mais elevado, integrado pelas serras e maciços litorâneos, com diferentes tipos de modelados de dissecação (BRICALLI, 2011). Essa unidade está presente na porção oeste da bacia, correspondendo os maciços aos maciços graníticos Mestre Álvaro, Morro do Vilante e Morro da Cavada e as colinas, às colinas metamórficas do Complexo Nova Venécia. 


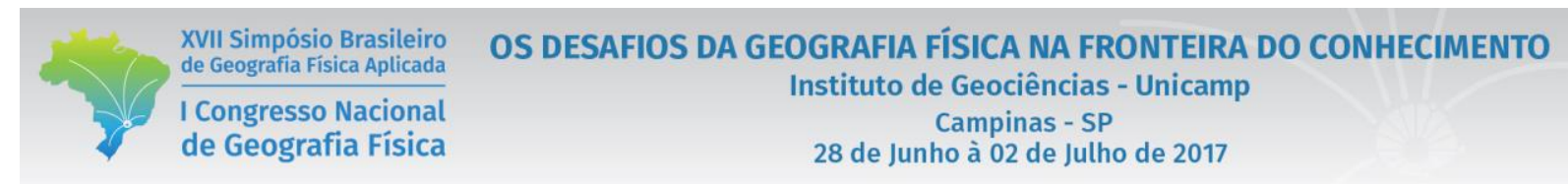

Os Tabuleiros Costeiros desenvolvem-se sobre os sedimentos da Formação Barreiras, correspondendo a colinas altas e baixas com topos alongados e tabulares, com altitudes variadas, de 30 a $200 \mathrm{~m}$ (GATTO et al., 1983). As vertentes são geralmente abruptas e, no litoral, terminam sob a forma de extensos tabuleiros ou falésias de vários metros de altura (BRICALLI, 2011). Este compartimento apresenta vales bem encaixados e as diferenças altimétricas podem estar relacionadas ao controle neotectônico (RIBEIRO, 2010). Essa unidade corresponde a maior parte da bacia.

A Planície Costeira encontra-se separada por maciços, colinas e tabuleiros, apresentando uma série de ambientes diversificados e complexos, afetados por oscilações eustáticas e climáticas e pelo controle de tectonismo regional (GATTO et al.,1983). A proximidade com o litoral é marcada pela influência marinha na formação de mangues.

\section{Materiais e métodos}

\subsection{Análises hipsométricas}

Foi elaborado um mapa hipsométrico a partir de um Modelo Digital de Elevação (MDE) - TOPODATA (VALERIANO, 2002), classificado em 5 (cinco) classes de altitude distintas: <8, 8-45, 45-100,100300,300-850 metros de altitude, com uso do software ArcGIS 10.1 TM (ESRI, 2012), escala 1:50.000.

3.2 Análise da rugosidade do relevo (ICR)

Foi gerado um mapa de rugosidade do relevo a partir do Modelo Digital de Elevação (MDE) TOPODATA (VALERIANO, 2002), utilizando o software ArcGIS 10.1 ${ }^{\mathrm{TM}}$ (ESRI, 2012),confeccionado a partir da realização de um mapa de declividade e em seguida a matriz de declividade foi convertida para um arquivo de pontos, onde cada ponto possui um diferente valor matricial atribuído. Posteriormente, avaliou-se estatisticamente a dispersão ou concentração do dado e, em seguida, foi definido o número de classes, a partir da reclassificação das classes de rugosidades geradas, para uma melhor representação do relevo da área.

\subsection{Perfil geológico-geomorfológico}

Para elaboração dos perfis geológicos-geomorfológicos foi traçado linha de corte, na direção onde se deseja representar as seções dos perfis, através da criação dos planos de informações de linhas. Em seguida, adicionou-se o modelo topográfico Triangular Irregular Network (TIN) no ArcGIS 10.1 TM (ESRI, 2012). A personalização do gráfico foi feita de forma manual, através da interpolação e traçado de polígonos, a partir das litologias presentes no mapa geológico do CPRM (2014). 


\subsection{Análises de campo}

Em campo foram realizadas análisadas, identificadas e validadas as variáveis litologia, estrutura geológica, altimetria, declividade de talude e rugosidade do relevo, feições morfotectônicas, morfologias e a relação entre todas essas variáveis. A identificação desses aspectos foi feita sobre bases cartográficas: cartas topográficas de Serra e Nova Almeida, com curvas de nível com equidistância de 20m (IBGE, 1978a; IBGE, 1978b), escala 1:50.000; Ortofotos digitais (IEMA, 2008), escala 1:50.000, resolução de 30m; Mapa Geológico (CPRM, 2014), escala 1:100.000; Mapa Geomorfológico (GATTO et. al, 1983), escala 1:1.000.000; além da utilização dos mapas hipsométrico e de rugosidade elaborados, na escala de 1:50.000. O registro dessas variáveis foi feito com a utilização de máquina fotográfica digital (resolução 24 megapixels) e GPS (Global Position System).

\subsection{Análises neotectônicas}

Os dados de neotectônica foram utilizados do trabalho de Bricalli (2011), presente em um afloramento na Formação Barreiras na bacia.

\section{Resultados e Discussões}

A bacia apresenta-se claramente associada a controles litoestrutural, litológico e neotectônico.

\subsection{Compartimento do Embasamento Pré-Cambriano}

A presença de lineamentos na direção NNW-SSE no Maciço Mestre Álvaro (Figura 1) pode estar relacionado a Faixa Colatina, com orientações predominantes NNW-SSE, região caracterizada pelas maiores densidades de lineamentos no estado do Espírito Santo (BRICALLI, 2011).Os lineamentos na direção NE-SW das rochas do Complexo Nova Venécia podem estar refletindo às orientações das falhas, fraturas e foliações de direção NE-SW, relacionadas à estruturação da Faixa Ribeira (MACHADO FILHO et al., 1983; PEDROSA SOARES e WIEDEMAN-LEONARDOS, 2000). 


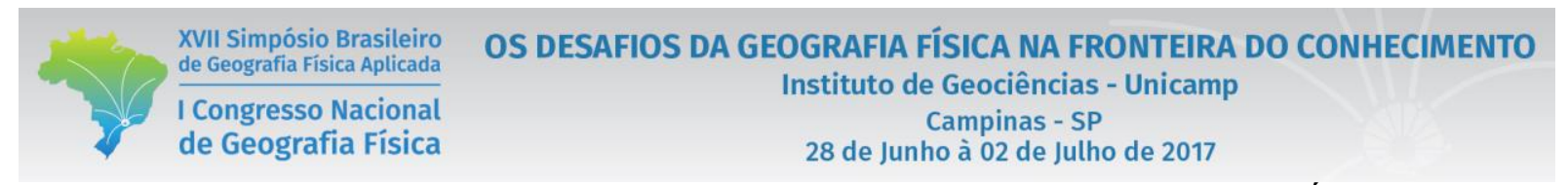

O controle litológico mostra-se evidente nas intrusões graníticas (Maciço Mestre Álvaro, Morro da Cavada e Morro do Vilante) que apresentam as altitudes mais elevadas (Figura 2) da bacia com relação às rochas metamórficas, uma vez que aquelas são rochas mais resistentes ao intemperismo e erosão (rochas ígneas) do que as rochas metamórficas (silimanita-granada-cordierita-biotita gnaisse bandado com intercalações de anfibolito e rochas calcissilicáticas).

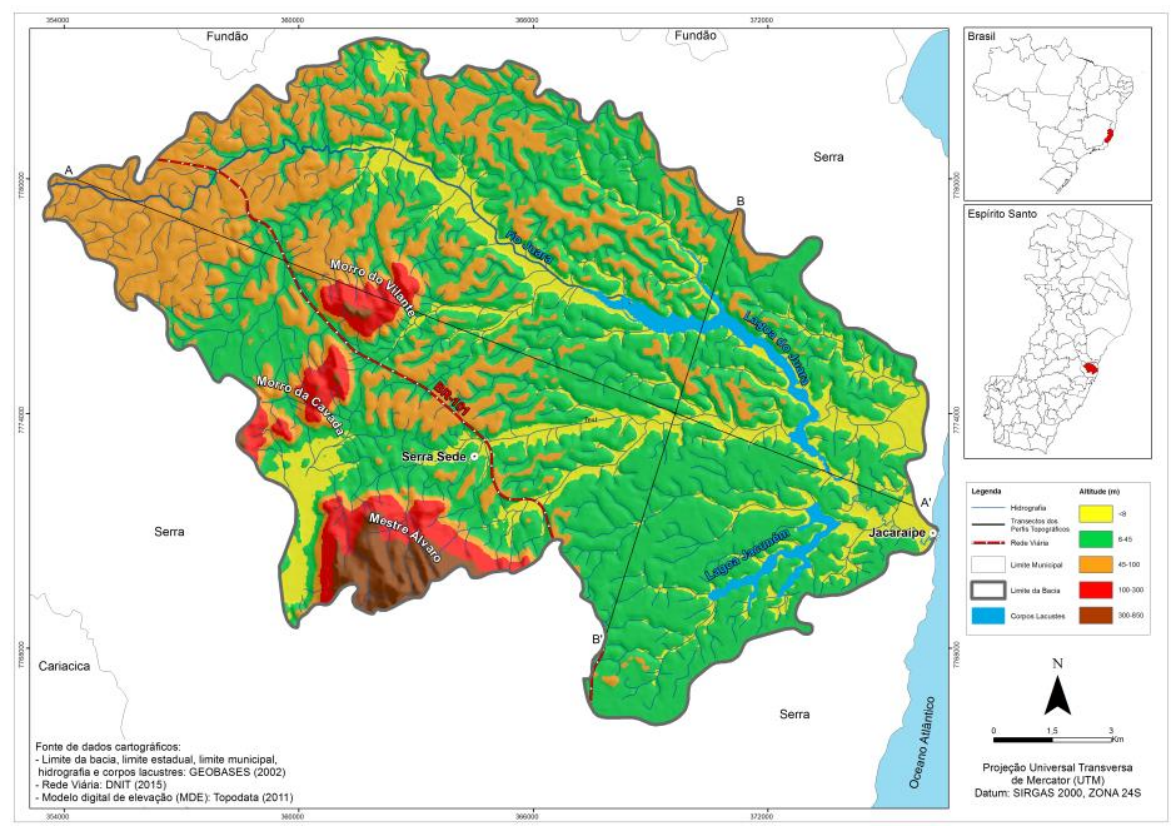

Figura 2 - Mapa hipsométrico mostrando as diferentes classes altimétricas presentes na bacia do rio Juara.

O Mapa de Índice de Concentração da Rugosidade (ICR) mostrou que as rugosidades mais baixas correspondem às rochas metamórficas e que as áreas com maior rugosidade correspondem, de uma maneira geral, às litologias mais resistentes ao intemperismo e, portanto, menos dissecadas (intrusões graníticas)- figura 3. 


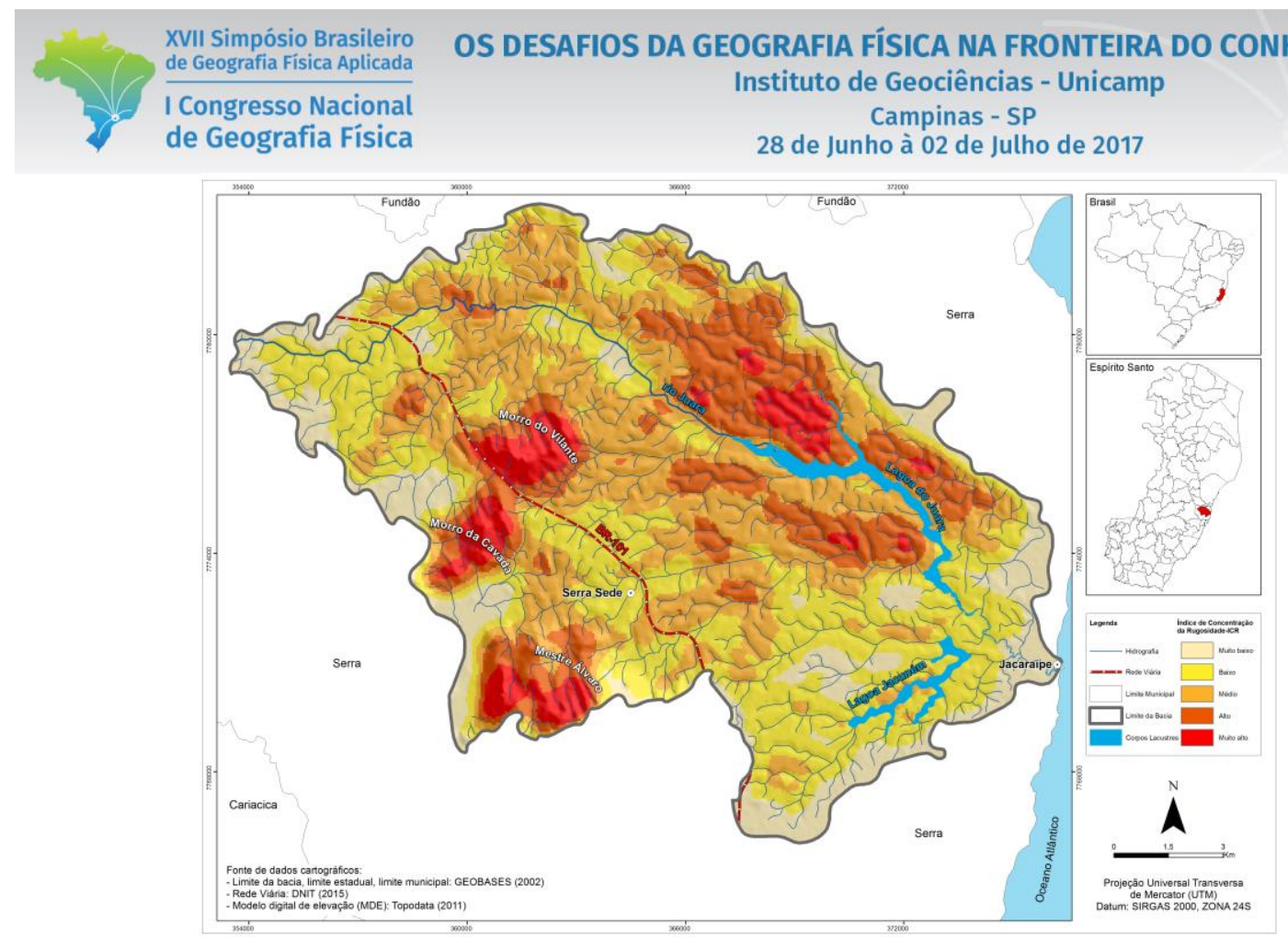

Figura 3 - Mapa de Índice de Concentração da Rugosidade (ICR) mostrando as áreas com alta, média e baixa declividade na bacia do Juara.

\subsection{Compartimento dos Depósitos Cenozoicos}

O compartimento dos Depósitos Cenozoicos, por sua vez, pode ser atribuído a padrões de fraturamento neotectônico descritos em trabalhos anteriores (RIBEIRO, 2010; BRICALLI, 2011) e a controle litoestrutural (BRICALLI, 2011).A orientação NW-SE e NNW-SEE do rio e da Lagoa do Juara (Figura 1) pode ser associada a estruturas geradas no evento de transcorrência dextral E-W (PleistocenoHoloceno), relacionando-se, respectivamente, a falhas dextrais WNW-ESE a E-W e falhas normais NWSE (BRICALLI, 2011).

A orientação NE-SW da Lagoa Jacuném (Figuras 1, 2 e 3) nessa mesma orientação, pode ser associada a padrões de fraturamento caracterizados por falhas normais NE-SW, relacionados a um regime tectônico distensivo de orientação NW-SE, atribuído a uma idade holocênica. As rochas sedimentares da Formação Barreiras apresentam altitudes diferentes, mesmo apresentando mesma origem e litologia. Esse fato pode estar relacionada a controle neotectônico na Formação Barreiras, uma vez que foram verificadas feições morfotectônicas e uma falha neotectônica na bacia. Além disso, a Formação Barreiras apresenta altitudes mais elevadas que as rochas metamórficas, fato esse que pode estar relacionado ao controle morfoestrutural (erosão diferencial) ou morfotectônico, uma vez que o relevo da Formação Barreiras pode ter sido soerguido por neotectônica, já que o mesmo encontra-se falhado (BRICALLI, 2011). 


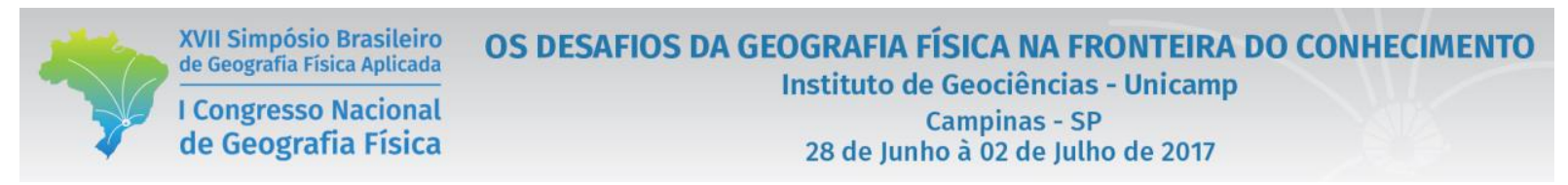

O mapa de rugosidade mostra que existe alta e muito alta índice de rugosidade na Formação Barreiras, demonstrando ser uma área pouco dissecada, contrastando com as rochas metamórficas do Complexo Nova Venécia, na porção noroeste da bacia. Essa rugosidade alta, precisa ser melhor investigada na área e relacionada a outros fatores, tais como momentos diferentes de deposição das rochas da Formação Barreiras, a despeito das outras partes na bacia ou comportamentos diferentes da incisão da drenagem nessa área.

As rochas sedimentares da Formação Barreiras apresentam altitudes diferentes, bem contrastantes, sendo que apresentam a mesma origem e litologia. Essa diferença altimétrica pode ser observada especialmente no perfil topográfico (Figura 4) e esse fato pode estar relacionada a controle neotectônico na Formação Barreiras, uma vez que foram verificadas feições morfotectônicas e uma falha neotectônica na bacia. Essa diferença altimétrica na Formação Barreiras também foi documentada no nordeste do Brasil (BEZERRA et al., 2001).

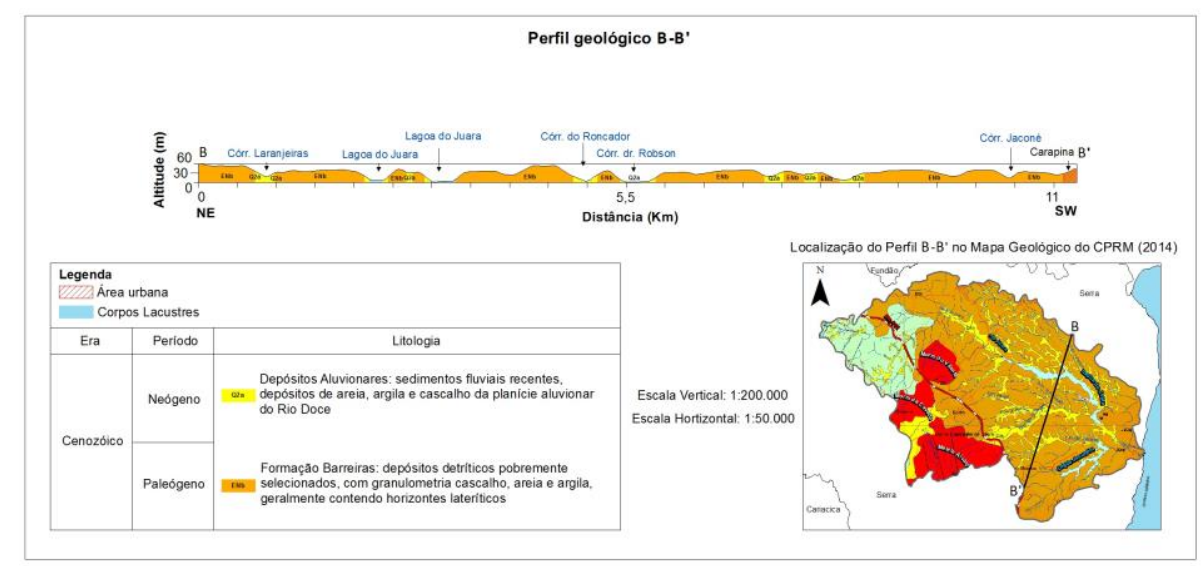

Figura 4 - Perfil Geológico-Geomorfológico (B-B') na orientação NNE-SSW, abrangendo e destacando todas unidades geológicas e geomorfológicas da bacia.

\section{Considerações Finais}

As análises dos mapas elaborados e os trabalhos de campo sugerem que a bacia do rio Juara está controlada pela litoestrutura, litologia e reflete as tensões neotectônicas, atuando diferentemente nas rochas do Embasamento Pré-Cambriano e nas rochas dos Depósitos Sedimentares.

Parece existir um condicionamento exercido por estruturas neotectônicas no relevo e na rede de drenagem da área investigada. O importante controle estrutural exercido pelo fraturamento de orientação NW-SE, por exemplo, na orientação do rio e na lagoa do Juara pode ser observado de modo particular em diversas bacias hidrográficas, como as bacias dos rios Barra Seca, São José, Piraquê-Açu, onde a orientação deste 
rio e de seus afluentes e o caráter assimétrico estão fortemente condicionados segundo esta direção (BRICALLI e MELLO, 2009; FORNACIARI, 2009; BUSATO, 2014; BUSATO e BRICALLI, 2015).

A análise da altitude (hipsometria e perfil topográfico) revela blocos altos e baixos em função da litologia e controle neotectônico. O relevo é marcado, nas intrusões graníticas, por front de escarpas, sugestivos de controles tectônico na área, a qual é caracterizada por evidências de movimentos crustais, com marcas de falhas, deslocamentos de blocos e falhamentos transversos, mostrando o controle estrutural sobre a morfologia, evidenciados no mapa geológico, hipsométrico. Na Formação Barreiras, esse fato parece estar relacionado a erosão diferencial nas diferentes litologias mas, também, possivelmente, a blocos rebaixados e soerguidos por tectônica, uma vez que grande parte da bacia é composta pela Formação Barreiras e esta apresenta-se controlada neotectônicamente (BRICALLI, 2011).

Durante os trabalhos de campo foram observadas feições típicas de origem tectônica nos dois compartimentos da bacia, tais como facetas triangulares, no Compartimento do Embasamento Précambriano; Alvéolos de sedimentação, vales estrangulados, lagos retilíneos, no Compartimento dos Depósitos Sedimentares, sugerindo controle neotectônico na bacia.

Dessa forma, é válido ressaltar, a importância de uma investigação de lineamentos e falhas neotectônicas em afloramentos na área, para que assim,se possa identificar o possível ou possíveis eventos neotectônicos responsáveis pelo controle morfotectônico e na rede de drenagem, indicados ao longo da pesquisa e verificados por outros autores (RIBEIRO, 2010; BRICALLI, 2011).

\section{Referências bibliográficas}

AB'SABER, A.N. Megageomorfologia do território brasileiro. In: CUNHA,.S.B.; GUERRA,A.J.T Geomorfologia do Brasil.Rio de Janeiro: Bertrand Brasil,1998.

BEZERRA, F.H.R; AMARO, V.E; VITA-FINZI, C; SAADI, A. 2001. Pliocene-Quaternary fault control of sedimentation and coastal plain morphology in NE Brazil. Journal of South American Earth Sciences, 14: 61-75.

GATTO, L.C.S; RAMOS, V.L.S; NUNES, B.T.A; MAMEDE, L; GÓES, M.H; MAURO, C.A; ALVARENGA, S.M; FRANCO, E.M.S; QUIRICO, A.F; NEVES, L.B. Geomorfologia. Projeto Radam Brasil. Folhas 23/24 Rio de Janeiro/Vitória .V 32. Rio de Janeiro, 1983.

BRICALLI, L.L; MELLO, C.L.Controle Neotectônico na rede de drenagem da bacia do rio Barra Seca (Porção emersa da Bacia do Espírito Santo). In: XII SNET (SIMPÓSIO NACIONAL DE ESTUDOS TECTÔNICOS),VI INTERNATIONAL SYMPOSIUM ON TECTONICS, 12, 2009, Ouro Preto (MG). Anais...Outro Preto: Xii Snet (Simpósio Nacional de Estudos Tectônicos), VI International Symposium On Tectonics, 2009, p.55.

BRICALLI, L. L. Padrões de lineamento e faturamento neotectônico no estado do Espírito Santo. 2011. 221 p. Tese, Instituto de Geociências - IGEO/UFRJ, DSc., Programa de pós-graduação em Geologia - Rio de Janeiro. 2011. 
BRICALLI, L. L.; MELLO, C. L. ; CIANFARRA, P.; SALVINI, F. Tectonic Implications from Manual and SemiAutomatic Analyses of Lineament Patterns in the Espírito Santo State (Southeastern Brazil). In: 47 CONGRESSO BRASILEIRO DE GEOLOGIA, 2014, Salvador. Anais do 47 CONGRESSO BRASILEIRO DE GEOLOGIA, 2014.

BUSATO, C. Landforms tectônicos e controle neotectônico na rede de drenagem da bacia do rio Piraquê-Açu (Espírito Santo-Sudeste do Brasil). Trabalho de Conclusão de Curso. (Graduação em Geografia) — Universidade Federal do Espírito Santo, 2014.

BUSATO, C.; BRICALLI, L. L. . Morfotectônica e Análise da Rede de Drenagem da Bacia do Rio Piraquê-Açu (Espírito Santo-Sudeste do Brasil). In: XV SIMPÓSIO NACIONAL DE ESTUDOS TECTÔNICOS(XV SNET), 2015, Vitoria. XV SIMPÓSIO NACIONAL DE ESTUDOS TECTÔNICOS IX INTERNATIONAL SYMPOSIUM ON TECTONICS. São Paulo: SBG, 2015. v. 1.

COSTA, J. A. V.; FALCÃO, M. T. Compartimentação morfotectônica e implicações de evolução do relevo do hemigráben do Tacutu no Estado de Roraima. Revista Brasileira de Geomorfologia, v.12, n.1, p.85-94, 2011.

COSTA, J. S. ; BRICALLI, L. L. . Caracterização geológica e geomorfológica da bacia do rio Santa Maria da vitória a partir de técnicas de geoprocessamento (Espírito Santo, sudeste do Brasil). In: GEOSUDESTE $201514^{\circ}$ Simpósio de Geologia do Sudeste $8^{\circ}$ Simpósio do Cretáceo do Brasil VI Simpósio Nacional de Ensino e História de Ciências da Terra, 2015, Campos do Jordão. Geosudeste 2015 - Anais. São Paulo: Sociedade Brasileira de Geologia, 2015. v. 1. p. 39-44.

CPRM - Companhia de Pesquisa e Recursos Mineirais, Serviço Geológico do Brasil. 2014. Carta Geológica de Vitória (ES). 1:100.000.

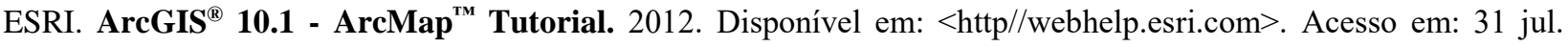
2012.

HASUI, Y. CARNEIRO, C. D. R, ALMEIDA, F. F. M. de A., BARTORELLI, A. Geologia do Brasil. 2012, 900p.

HEILBRON, M.; PEDROSA-SOARES, A. C.; CAMPOS NETO, M. C.; SILVA, L. C.; TROUW, R. A. J.; JANASI, V. A. Província Mantiqueira. In: MANTESSO-NETO, V. M.; BARTORELLI, A.; CARNEIRO, C. D. R.; BRITONEVES, B. B. (orgs.). Geologia do Continente Sul-Americano: evolução da obra de Fernando Flávio Marques de Almeida. São Paulo: Editora Beca, 2004. p. 203-234.

IBGE - Instituto Brasileiro de Geografia e Estatística (IBGE). 1978a. Carta Topográfica do Brasil. Folhas SF-24V-B-I-1 (Serra). Escala 1: 50.000.

IBGE - Instituto Brasileiro de Geografia e Estatística (IBGE). 1978b. Carta Topográfica do Brasil. SF-24-V-B-I-2 (Nova Almeida). Escala 1: 50.000.

IEMA- Instituto Estadual de Meio Ambiente e Recursos Hídricos do Estado do Espírito Santo. Ortofotos Digitais. 2008.

MACHADO FILHO, L.M; RIBEIRO, M.W; GONZALEZ, S.R; SCHENINI, C.A; NETO, A.S; PALMEIRA, R.C.B; PIRES, J.L; TEIXEIRA, W; CASTRO, H.E.F. Geologia. Projeto Radam Brasil. Folhas 23/24 Rio de Janeiro/Vitória .V 32. Rio de Janeiro, 1983.

MARIN, S. P. ; BRICALLI, L. L. . Anomalias e Padrões de Drenagem da Bacia do rio Formates e Correlação com a Geologia e Deformação Neotectônica no Estado do Espírito Santo (Sudeste do Brasil). In: GEOSUDESTE 2015 ,14 Simpósio de Geologia do Sudeste $8^{\circ}$ Simpósio do Cretáceo do Brasil VI Simpósio Nacional de Ensino e História de Ciências da Terra, 2015, Campos do Jordão. Geosudeste 2015. Anais... São Paulo: Sociedade Brasileira de Geologia, 2015. v. 1. p. 14-18.

MARQUES NETO, R.; PEREZ FILHO, A. Compartimentação morfoestrutural da bacia do rio verde, sul de Minas Gerais. Revista Brasileira de Geomorfologia, v.15, n.1, (Jan-Mar) p.119-135, 2014.

MENKE, A. B.; GUIMARÃES, R. F.; OLIVEIRA, S. N.; GOMES, R.; CARVALHO JÚNIOR, O. A. Compartimentação geomorfológica preliminar do Rio Ipanema (AL/PE) utilizando análise multivariada em bacias hidrográficas de 1a ordem. In: VII Simpósio Nacional de Geomorfologia \& II Encontro Latino-Americano de Geomorfologia, 2008, Belo Horizonte. Anais... Belo Horizonte: VII Simpósio Nacional de Geomorfologia \& II Encontro Latino-Americano de Geomorfologia, 2008. 
PEDROSA-SOARES, A.C; WIEDEMANN-LEONARDOS, C.M.2000.Evolution of the Araçuaí Belt and its connection to the Ribeira Belt, Eastern Brazil. IN: CORDANI,U.G; MILANI, E,J; THOMAZ FILHO, A; CAMPOS, D.A (ed.)Tectonic Evolution of South America.2000. p. 265-285.

RIBEIRO, C.S. Influência da tectônica pós-deposicional na distribuição da Formação Barreiras entre o rio Paraíba do Sul (RJ) e o rio Doce (ES). 2010. 164 p. Dissertação (Mestrado em Geologia) - Instituto de Geociências, Universidade Federal do Rio de Janeiro, Rio de Janeiro, 2010.

SALAMUNI, E.; NASCIMENTO, E.R; SILVA, H.A.P; FIORI, O.C. Geomorfologia do Município de Curitiba-PR. Revista Brasileira de Geomorfologia. n 14. n4. 2013.

SCHIRMER, G. J.; ROBAINA, L. E. de S. Compartimentação de unidades geomorfológicas do município de Agudo/RS. Revista Brasileira de Geomorfologia. v.14, n.1, (Jan-Mar) p.03-12, 2013.

TRENTIN, R.; SANTOS, L. J. C.; ROBAINA, L. E. de S. Compartimentação geomorfológica da bacia hidrográfica do rio Itu - Oeste do Rio Grande do Sul - Brasil. Soc. \& Nat., Uberlândia, ano 24 n. 1, 127-142, jan/abr. 2012.

XAVIER, A. R; NETTO, C.L.A. Caracterização Geomorfológica da Bacia do rio Turvo-RJ:Médio Vale do rio Paraíba do Sul (MVPRS). Revista Brasileira de Geomorfologia. V.15.n1.2104 